\title{
20 years of graduate optics education at the University of New Mexico
}

Marek Osiński, Kenneth Jungling, Mansoor Sheik-Bahae, Sudhakar Prasad, John Mclver, et al.

Marek Osiński, Kenneth C. Jungling, Mansoor Sheik-Bahae, Sudhakar Prasad, John K. Mclver, Arthur H. Guenther, "20 years of graduate optics education at the University of New Mexico," Proc. SPIE 9663, Eighth International Topical Meeting on Education and Training in Optics and Photonics, 966313 (6 October 2003); doi: 10.1117/12.2207483

SPIE Event: Eighth International Topical Meeting on Education and Training in Optics and Photonics, 2003, Tucson, Arizona, United States 


\title{
20 years of graduate optics education at the University of New Mexico
}

\author{
Marek Osiński, Kenneth C. Jungling \\ Department of Electrical and Computer Engineering, University of New Mexico, Albuquerque, New Mexico 87131 \\ Telephone +1 505 272-7812; Fax +1 505 272-7801; E-mail: osinski@chtm.unm.edu
}

Mansoor Sheik-Bahae, Sudhakar Prasad, John K. McIver

Department of Physics and Astronomy, University of New Mexico, Albuquerque, New Mexico 87131

\author{
Arthur H. Guenther \\ Center for High Technology Materials, University of New Mexico, Albuquerque, New Mexico 87106-4343
}

\begin{abstract}
The year 2003 marks the $20^{\text {th }}$ anniversary of introducing interdisciplinary graduate optics education at the University of New Mexico. The Ph.D. program in Optical Sciences has produced over 75 graduates. A new M.S. program in Optical Science and Engineering, introduced in Fall 2002, is rapidly gaining popularity. This paper reviews both programs, focusing on their unique features.

(C2003 Optical Society of America

OCIS codes: (000.2060) Education
\end{abstract}

\section{Introduction}

For the past 20 years, the Departments of Physics and Astronomy (P\&A) and of Electrical and Computer Engineering (EECE) at the University of New Mexico (UNM) have jointly administered a highly successful interdisciplinary, intercollegiate Ph.D. program in Optical Sciences. During this interval, over 75 Ph.D. degrees have been awarded to graduates who have become highly valuable members of optical industries and academia here and abroad. During this same period, the optics-related faculty has seen its numerical strength increase to nearly 30 , and has expanded into several departments such as Biology, Chemistry, Mathematics and Statistics, Chemical Engineering, and Mechanical Engineering.

The graduate program in optics at UNM is evolving continually to adapt to the growing needs of the entire optics enterprise of industries, federal laboratories, and academic institutions. Over the last few years, attention has turned to the establishment of a Master's degree in Optical Science and Engineering (OSE) at UNM. A distinctive feature of the new multi-disciplinary degree is its unique Internship option, which allows a student to spend six months to a year at a participating industry or a federal/national laboratory working on a scientific project of mutual interest. Additionally, the Internship would accord the industries and labs a first-hand look at prospective employees and ability to "pre-train" them, creating in the process further collaborative activities between UNM and optics industry/labs. In these ways, the new degree is expected to fulfill a long-standing need for industrial and lab personnel that are well trained in relevant and meaningful ways to meet the challenges of the $21^{\text {st }}$ century. The desirability of a Master's degree is substantial in other respects too, particularly for short-term retraining of already employed optics personnel, for giving the university a stronger role in creating business opportunities and economic benefits that would result from a broader interaction with industrial and government laboratories, and for creating an optics career path with multiple exit points. The new degree has received strong support from the New Mexico Optics Industry Association (NMOIA), which represents a large number of optics industries in the State of NM, and from a variety of other organizations which see substantial overall benefits to the State from such a program.

Currently, 9 students are enrolled in the M.S. in OSE program through the P\&A Department, and 7 through the EECE Department. Corresponding enrollment numbers for students in the Ph.D. in OSE program are 29 through P\&A, and 16 through EECE. These numbers are expected to grow steadily in the future years, especially when the new B.S. in OSE degree program, presently in its advanced planning stages, is introduced.

\section{The setting}

The rustic setting of New Mexico populated along the meandering waters of the Rio Grande belies the hubbub of intense industrial and scientific activity in its three major research universities, three federal laboratories, and numerous industrial establishments. The state that is sometimes confused for the country it borders to its south boasts a long tradition of pioneering research in science and technology, ranging from the heady times of rocketry 
and the harnessing of nuclear energy through the cold-war era of quiet but highly prominent research in optical imaging and reconnaissance at the Air Force Research Laboratory. The present times definitely belong to optics and photonics, a discipline that has long played - and continues to play - the role of enabling a vast number of important technologies ranging from manufacturing to biomedical engineering to modern high-bandwidth communication to highly efficient, bright display devices.

Nestled between the foothills of the majestic Sandia Mountains and the idyllic Rio Grande river, Albuquerque, the largest city in New Mexico boasts frequent spectacular double rainbows as well as an array of national and federal laboratories, numerous optics and photonics industries, and a Carnegie Doctoral/Research university with a major degree program in optics. Research and education in optical science and engineering have a long, distinguished history in New Mexico, and the two aspects of optics have strengthened each other, in particular over the past two decades. And the university that has led a lot of this activity was accorded the status of the fastest growing research institution in the country just four years ago, when measured in terms of the overall federal research dollars attracted.

UNM joined the ranks of the Universities of Rochester and Arizona in 1983 with its Ph.D. program in Optical Sciences, established by the joint will of its Physics and Astronomy (P\&A) and Electrical Engineering and Computer Engineering (EECE) departments. Currently one of only five major graduate degree programs in optics in the US, UNM's program sets itself apart, already at inception, from its two more illustrious original peers, Arizona and Rochester, by choosing a cross-disciplinary focus as its principal motivation. In this respect, it anticipated by fifteen years the findings of the now widely cited, comprehensive COSE report of the National Research Council, 1998, which proclaimed:

"Universities should encourage multidisciplinarity in optics education, cutting across departmental boundaries, and should provide research opportunities at all levels, from the bachelor's degree to the doctorate and from basic science to applied technology."

The Ph.D. program at UNM has produced over 75 optics Ph.D.'s, all well employed in a variety of national and international settings. The two participating departments have shared in the design and teaching of the core and ancillary courses and performed pace-setting research in many areas, notably ultrafast optics and photonics, highresolution imaging, quantum optics, optoelectronic devices, fiber amplifiers, optical materials, and novel optical lithography. The breadth and depth thus attained by the program have unquestionably created a world-class training, education, and research facility at UNM.

Led by twenty optics faculty members spread equally over the two participating departments, the graduate program in optics is supported by 5,000 sq. ft. of research laboratory space within P\&A and a new 60,000-sq.ft. Center for High Technology Materials (CHTM) building with 18,000-sq.ft. of dedicated space for optoelectronics and laser research. The facilities and instruments at the disposal of our students in these buildings include a 4,000sq.ft. class-100 clean room and several class-10,000 clean rooms, microlithography and thin-film deposition facilities, two MOCVD and one MBE crystal-growing facility; several short-pulse laser systems, including highpower femtosecond UV and Ti:sapphire as well as fiber lasers and amplifiers, dye and solid-state lasers; and a variety of other instruments that include materials diagnostic apparatuses like scatterometer, ellipsometer, $\mathrm{x}$-ray diffraction probes, etc. and photolithographic, vacuum processing, and related systems.

Each year, only a small fraction of the applicants to the Ph.D. program are admitted. Almost without exception, those accepted are supported by a number of teaching and research assistantships dedicated to this degree program.

A key beneficiary of a strong optics education and research program at UNM has been optical astronomy and imaging. Imaging has great relevance to the Air Force, which has strong research in these areas at its Research Laboratory (AFRL) at the Kirtland Air Force Base (KAFB) and has supported important imaging projects at UNM. The precious dark skies of NM have rendered excellent astronomical opportunities and led to world-class observational facilities like the Very Large Array near Socorro just eighty miles away, the National Solar Observatory near Cloudcroft about two hundred miles away, a large telescope outfitted with state-of-the-art adaptive optics system at the Starfire Optical Range (SOR) at KAFB, among others. The role of optics at UNM is also considerable for UNM's Lodestar project, a federally and state-funded thirty-million -dollar program to create a state-wide educational and research infrastructure in astronomy from the grade levels to the most advanced doctoral research levels.

Very noteworthy developments in high-power lasers, including the chemical oxygen-iodine laser (COIL), the $\mathrm{CO} 2$ laser, and the CO laser, at AFRL have led to further collaborative projects at UNM. Similarly important collaborations, including laser-induced cooling, have marked our relationship with the Los Alamos National Laboratory (LANL), only ninety miles away, and with the Sandia National Laboratory (SNL) located within the city limits. 
The unique local setting of the three important government laboratories, AFRL, LANL, and SNL, and their cooperative venture with UNM's Center for High Technology Materials (CHTM) under the Alliance for Photonic Technology (APT) have led to a strong emerging collaboration with US industries. The connection with numerous local optics industries has been further bolstered by the active presence of the recently formed NMOIA. The combination of APT and NMOIA provides for a formidable collaborative infrastructure for optics education and research in New Mexico.

\section{Early history}

Through the 1960's and 70's there emerged two universities in the United States where optics was an important component of the curriculum and research program. Through the 70's both of these institutions have grown and prospered. These are the University of Rochester, long noted for its interest, emphasis, and research on optics, and the Optical Sciences Center at the University of Arizona, formed in response to the perceived need for increased activity in optics in early 1970's. By 1980, these two institutions trained the bulk of graduates in the optical sciences at the M.S. and Ph.D. degree levels. Of the roughly 70-80 Ph.D.'s in optics graduated each year in the United States, about 20 came from the University of Rochester, 20 from the Optical Sciences Center at the University of Arizona, and the rest from the 20 or so departments around the country, with each of which producing 1-2 graduates a year.

Through the decade of 1970's, optics-oriented industries have been formed and have expanded at a rapid rate. By 1978 , over $\$ 5$ billion per year was being spent by industry and Government on optics and optical systems. There were more than 1,000 optical scientists, and in the Albuquerque area alone there were about a dozen companies involved in optics research. Most of these provided services via contract to programs at Kirtland Air Force Laboratory, Sandia National Laboratories, o Los Alamos National Laboratory.

By the end of 1970's, officials of these companies and laboratories were urging UNM to establish an optics program. The advantage was clear and three-fold. First, it would provide the much-needed manpower base to these companies and federal laboratories; second, it would provide an opportunity for New Mexicans to gain education in this rapidly developing field and find excellent employment opportunities locally; third, it could provide for retraining or upgrading the skills of personnel working on optical projects for local laboratories. For example, the Kirtland Air Force Laboratory was sending their scientists for a year to the Optical Sciences Center at the University of Arizona to be retrained in the optical sciences area. The cost and logistical disadvantages associated with this approach were clear. It would be of great assistance to the programs at Kirtland if training opportunities in the optical sciences were available locally.

In 1980/81 the P\&A Department established a research and instructional group called the Institute for Modern Optics (IMO). The original personnel consisted of Marlan Scully and his research group who joined UNM from the Optical Sciences Center at the University of Arizona in 1980. In the first year the following courses were established and offered through the P\&A Department: 476L/447L - Experimental techniques of Optics, 554 - Advanced Optics I, 555 - Advanced Optics II, 556 - Electro-Optical Physics, 564 - Laser Physics I, 565 - Laser Physics II, 566 Nonlinear Optics and High Power Lasers. These new courses along with previously established graduate courses in physics allowed the department to offer the basics of advanced optics and laser physics.

The response to this expanded academic program was very positive. Enrollment in graduate-level courses was rising. A substantial fraction of the enrollment was from scientists and engineers who were not otherwise pursuing a university degree. Through their experience with the courses offered in 1980/81 and through numerous discussions with scientists and administrators in local industry and federal laboratories, the IMO group reached the conclusion that there was strong local interest in a broader range of courses in the area of optics, laser optics, and optical systems engineering, and that there was a significant demand for a degree program in optical sciences and engineering.

Recognizing the truly interdisciplinary natire of optics, with elements of physics, applied physics, materials science, and engineering, the IMO group proposed establishment of a new interdisciplinary degree program at UNM, with initial participation from the P\&A and EECE departments, as well as from IMO.

In the late 1970s and early 1980s, the EECE Department developed its interest in the area of microelectronics. In 1981, a departmental report formulated "plans to focus on the areas of microelectronics and computer engineering. These are two areas in which they expect the most significant growth over the next ten years." Two years later, in 1983, the EECE Department established an Endowed Chair in Microelectronics with the financial backing of the city of Albuquerque and the state of New Mexico and, at the same time, established the Institute for Microelectronics and Thin Films (IMTF). During this period, the EECE Department and the Physics Department under the guidance of Dr. Scully established a joint Ph.D. program in Optical Science and Engineering. These 
developments came about due to the continued growth of the field of microelectronics and optoelectronics, the newest research and teaching interest in the Department.

The first recipient of the endowed chair in microelectronics was William Streifer, who in 1985 joined UNM and became the Director of the CHTM. Following the arrival of the new director, the CHTM was reorganized to include the IMO and the IMTF. Each institute became an interdepartmental entity reporting directly to the center director. To assist the director, coordinators have been appointed for each institute; specifically, Charles Hart in the IMO and Kenneth Jungling in the IMTF.

The first home of the CHTM under William Streifer's tenure was the Tapy Hall, the building named after Ralph W. Tapy who headed the Electrical Engineering Department from 1939 till 1952. The building also housed part of the overcrowded EECE department that occupied also part of the Farris Engineering Center, the Mechanical Engineering Building and the Old Lecture Hall.

Under William Streifer's leadership, strong focus on research in optoelectronics was established at CHTM, and this area has remained the main activity at CHTM till present. In 1986, Steven Brueck became the new director of the CHTM. He continues to lead the Center till today.

In 1982 a state-issued building bond came to maturity. Under the leadership of Chairman Peter Dorato, construction of the new EECE building started. The much-needed structure was completed in the summer of 1986 and continues to house the EECE Department to this day. CHTM has moved to the basement of this new EECE/Centennial Library building and stayed there until 1997, when it was transferred to a newly dedicated building located in the Science and Technology Park on south campus of UNM.

Already in 1980/81, 7 optics-related graduate-level courses were offered at the P\&A Department, and 3 more were offered by 1982/83, focusing heavily on laser physics. In parallel, 7 optics-related graduate-level courses were proposed by 1982 at the EECE Department, with emphasis on optical design and testing. While some of these early offerings still remain in the core of the Ph.D. program, many new courses have since been developed, particularly in the areas of semiconductor optoelectronics and photonics.

\section{Optics faculty at UNM}

Currently, nearly 30 faculty members participate in OSE graduate programs. While most of them are affiliated with either P\&A or EECE departments, several faculty associated with the program reside in other departments in the College of Arts and Sciences and in the School of Engineering. The following list identifies the participating faculty and briefly summarizes their research interests.

Alejandro Aceves, Mathematics \& Statistics: Nonlinear optics, nonlinear dynamics

James A. Brozik, Chemistry: Spectroscopy

Steven R. J. Brueck, EECE: Imaging interferometric lithography, extending optics to fundamental limits

Carlton Caves, P\&A: Quantum information theory and quantum measurement theory, particularly on ways of using quantum mechanics to perform information-processing tasks that cannot be performed classically

Christos Christodoulou, EECE: Helical THz antennas on semiconductor substrates, finite-difference analysis of phased array antennas, smart antennas in wireless communications, neural networks and modeling of electromagnetic systems

L. Ralph Dawson, EECE: MBE growth of narrow gap III-V semiconductors, like group-III antimonides, for detectors and emitters

Ivan H. Deutsch, P\&A: Quantum information theory with emphasis on atomic-molecular-optical implementations based on laser cooled and trapped atoms

Jean-Claude Diels, P\&A: Experimental investigation of ultrafast phenomena, development of femtosecond laser sources, optical imaging using femtosecond range gating, nonlinear opitcs

Petr G. Eliseev, EECE: Semiconductor lasers, quantum dots

Arthur H. Guenther, EECE: Laser applications to pulsed power technology, laser induced damage to optical materials, optics in defense, optics education

Majid Hayat, EECE: Optical communication, modeling and optimization of avalanche photodiodes, design and performance analysis of ultrafast optical links, statistical communication theory, signal detection and estimation, statistical image and signal processing, nonuniformity correction algorithms for infrared focalplane array sensors, imaging through turbulence, communication networks, congestion modeling and control

Stephen D. Hersee, (Ph.D., Brighton Polytechnic, 1975), EECE: MOCVD growth of III-V semiconductors

Diana Huffaker, EECE: Crystal growth (MBE, MOCVD) and characterization of novel materials for optoelectronic devices, growth methods and characterization of quantum dots for single photon, single electron based 
devices, photonic lattice fabrication and characterization, optical interconnects and integrated optoelectronics based on VCSEL technology

Ravi Jain, EECE: Quantum electronics, optoelectronics, electro-optics, experimental solid-state physics

V. M. Kenkre, P\&A: Theory of light-matter interactions in organic materials, exciton formation and dynamics, laser damage and ultrafast processes

Sanjay Krishna, EECE: Mid-infrared detection using self-organized quantum dots (QDs) and novel antimonidebased materials grown by molecular beam epitaxy

Luke Lester, EECE: Quantum dot lasers, mid-IR semiconductor lasers, and tunable lasers

Gabriel J. Lopez, Chem. \& Nuclear Eng.: Self-assembled nanostructures

Kevin Malloy, EECE: Coherent states in semiconductors, disorder in ionic semiconductors, wave propagation in periodic structures

Jack McIver, P\&A: High-power lasers

Marek Osiński, EECE: Semiconductor lasers, optoelectronic devices and materials, group-III nitrides, degradation mechanisms and reliability, computer simulation, optoelectronic integrated circuits

Sudhakar Prasad, P\&A: Classical and quantum optics, particularly the application of optical fibers in imaging interferometers, studies of sensitivity and resolution of such interferometers, statistical information in interferometric image processing, and studies of quantum noise in resonant atom-field interaction

Wolfgang Rudolph, P\&A: Ultrashort laser pulses and spectroscopy, femtosecond microscopy, infrared lasers

Edl Schamiloglu, EECE: Plasma physics, charged particle beams, electromagnetic wave propagation

Thomas Shay, EECE: Free-space optical communications through clouds, quantum cryptography, lasers

Mansoor Sheik-Bahae, P\&A: Laser cooling of solids, ultrafast phenomena, nonlinear optics

Stephen A. Stricker, Biology: Optics in microbiology

Scott Tyo, EECE: Ultra wideband antennas and radiation, optical and microwave remote sensing, hyperspectral and polarimetric imagery, metamaterials and artificial dielectrics

James Thomas, P\&A: Biological applications of ultrafast spectroscopy

Krzysztof Wódkiewicz, P\&A: Quantum optics

\section{Ph.D. in Optical Science and Engineering}

The requirements for the Ph.D. degree in OSE include:

- 52 hours of course work for credit, including 30 hours in required courses. To account for the diversity of interests in Optics, the 30 credit hours of required courses have been divided into two categories (see A and B below);

- 18 dissertation credit hours;

- Comprehensive Exam;

- Dissertation and defense

A. Mandatory courses (27 credit hours): Advanced Optics I (Physics 463 or EECE 463)

Advanced Optics II (Physics 554 or EECE 567)

Laser Physics I (Physics 464 or EECE 464)

Mathematical Methods in Physics (Physics 466 or Math 466)

Electromagnetism (Physics 511 or EECE 561)

Quantum Mechanics I (Physics 521) or Semiconductor Properties (EECE 572)

Nonlinear Optics (Physics 555 or EECE 568)

Optics Lab (Physics 476L or 477L)

3 credit hours of seminar, including one Optics seminar

B. Option-based courses ( 3 credit hours):

Solid State (Physics 530) or Semiconductor Properties (EECE 572)

Topics in Modern Optics (Physics 569)

Fundamentals of Optical Fiber Communication Systems (EECE 565)

Guided Wave Optics (EECE 564)

Mathematical Methods of Physics (Physics 467)

Laser Physics II (Physics 564) or Semiconductor Laser I (EECE 577)

Quantum Mechanics II (Physics 522) 
Quantum Optics (Physics 566)

The remaining 22 credit hours of coursework can be satisfied with a combination of "B" courses (500 level or above), including problem courses and research hours.

\subsection{The Optics Comprehensive Exam}

The Optics Comprehensive Exam is offered at the beginning of each Fall term concurrently with the Physics and EECE Comp Exams, and is based on material derived from Physics 463 or EECE 463, Physics 554 or EECE 567, Physics 464 or EECE 464, and Physics 511 or EECE 561. The exam itself consists of three parts - within 12 months of successfully completing the written and oral exams, a presentation by the student must be accepted by a committee. The intent of this presentation is to show that the student (i) has found a dissertation advisor, (ii) has formed a dissertation committee, and (iii) has started with research. Possible presentations are, for example, the defense of a research project or a dissertation proposal. Students do not advance to candidacy and, therefore, are not eligible to register for dissertation hours (699), until the presentation has been approved by the committee.

\subsection{The Oral Exam}

All students who take the written section of the Optics Comprehensive Exam are administered an oral exam by their Committee on Studies. Exception to this ruling is only rarely permitted, and is decided by the Committee on Studies prior to scheduling the oral exam. The Optics Graduate Committee is the body empowered to make the final decision on the Committees' pass/fail recommendations

\subsection{The Dissertation Proposal}

After passing the comprehensive exam, the student is expected to either obtain a dissertation research problem from a faculty member, or to formulate an independent dissertation proposal. The student should present this dissertation proposal to his or her Dissertation Committee as soon as possible, but no later than one year after the date of passing the Comprehensive Exam. At least two members of the Dissertation Committee, including the Chair, should be Optics faculty. If the dissertation proposal is deemed adequate as a starting point for a Ph.D. dissertation, then the student can formally advance to candidacy and begin dissertation work.

\section{M.S. in Optical Science and Engineering}

Over the years, a strong need for Master's program in Optical Science and Engineering (OSE) has been felt by students an faculty alike. A survey among the optics students in the Ph.D. program carried out few years ago showed an overwhelming support for an M.S. degree. Contact with national laboratories in Albuquerque are, namely Sandia National Labs., Air Force Research Lab. (Kirtland AFB), and Los Alamos Research Lab., has also revealed great interest in such a program. Market surveys done both by the National Research Council (NRC) and SPIE were also indicating a growing need for short-haul specialized training, as provided ideally by the Master's degree rather than the Ph.D. In particular, a study by the NRC, completed in 1998, on the state of optics and photonics was unequivocal in its prediction that the need for well trained optics personnel at all levels in industrial settings will easily outstrip their supply from the relatively few institutions that offer specialized optics degrees.

With the overwhelming evidence to indicate the desirability of the Master's program, further strengthened by enthusiastic endorsements from New Mexico Optics Industry Association, Albuquerque Economic Development, Inc., NM Department of Economic Development, and the Albuquerque Chapter of the Optical Society of America, a plan for a new M.S. in OSE degree was formulated in January 1999. Similarly to the Ph.D. program, the Master's program was prepared as an interdisciplinary offering, administered jointly by the P\&A and EECE departments. The process of formal approval of the program at various university and state levels was completed in May 2002, when the State Board of Finance acting upon recommendation from the Commission for Higher Education voted to approve the program. The first students were recruited into the Master's program in Fall 2002. Some students transferred from the pre-existing Ph.D. in Optical Sciences into the Master's program, which resulted in the first M.S. alumna graduating already in the first semester it was offered.

In order to emphasize the equal role played by both P\&A and EECE departments and to re-align the M.S. and $\mathrm{Ph}$.D. curricula so that they would be well articulated, the name of the Ph.D. program has been changed to Ph.D. in OSE.

Recognizing that many M.S. students will be interested in working in industry or in the national laboratories upon their graduation, the program has an attractive option of industrial/government laboratory internship lasting 
between six and twelve months. Short quarterly reports, as well as a comprehensive final report, must be submitted by the students to a committee consisting of a faculty liaison, another member of the optics faculty, and the student's industrial or lab supervisor. An Industrial/National Lab Advisory Committee, consisting of R\&D representatives from actively participating industry and labs, has been formed and is serving to further develop, refine, and oversee the internship option.

The M.S. degree in Optical Science and Engineering was approved enthusiastically in May 2002 both the NM Commission for Higher Education and the NM State Board of Finance. Throughout its approval process through various university and state level committees and agencies, the program has received strong, often unreserved, endorsement as one fulfilling the vision of broad-based optics education, as well as enhancing and completing the highly successful graduate optics program which has already produced over $75 \mathrm{PhD}$ 's. The MS program is an industrially driven initiative that is likely to help the NM optics industry meet its workforce needs from a local pool of uniquely qualified graduates. A similar industrial pulling led to the establishment of a new Associate of Applied Science (A.A.S.) degree program in photonics at the Albuquerque Technical Vocational Institute (TVI) in 2001. That program has already shown great promise in attracting large numbers of students, and is well deserving of its billing as an excellent model for production of highly skilled technicians for an industry that is likely to define and steer the economic development of the state and the nation in the new century. The new M.S. degree program at UNM has similarly drawn enthusiastic support from the entire spectrum of governmental and industrial establishments.

Like the Ph.D. program, the M.S. degree is being administered jointly by the departments of P\&A and EECE. The joint involvement of a science and an engineering department in UNM's graduate optics program underscores the cross-disciplinarity of this field.

The M.S. in OSE program has three different tracks to the degree, all of which share a required set of six courses divided equally between the basic science and engineering emphases of the field, but permit a student to either (i) complete further course work only or (ii) undertake research thesis work or (iii) sign up for an internship course along with other courses to complete the requirements of the degree. It is under option (iii) that a student will be able to perform a 6-month (to a year-long) internship either at an industry or at a federal government laboratory. This unique option, not available at any of the other four major optics programs in the country, will provide new opportunities for industry to supervise and evaluate potential future employees, to send its existing employees for further training, and for graduating students to preview and evaluate industrial career options. An Industrial/Laboratory Advisory Committee, consisting of representatives of NM's commercial and government R\&D sectors, will work closely with the Optics Graduate Committee at UNM to provide oversight needed to run this internship degree option effectively and adaptively with regard to evolving industrial needs and priorities.

Overall, the MS degree in Optical Science and Engineering at UNM will fill a unique role in the exploding optics enterprise of the state. By creating a local pool of highly skilled work force in this most important industrial sector, it will contribute significantly to defining the industrial economy of the state and the country for years to come.

\subsection{M.S. curriculum}

Plan I (thesis-based), a minimum of 24 hours of coursework and 6 hours of thesis credit (Physics 599) is required. Students must consult with a faculty member (Thesis Chair) about a research topic, and make a thesis proposal to the student's Thesis Committee very shortly thereafter. The student must write an approved manuscript and successfully defend the thesis in a manner analogous to a Ph.D. dissertation defense.

Plan II-a (course-based) requires a minimum of 33 hours of coursework, including 3 hours of advanced seminar (Physics 500) or graded problems (Physics 552/EECE 551) or graded research (Physics 650/EECE 651) - and at least 2 of those hours must be in Optics. No more than 6 hours of 400-level Physics/EECE coursework (excluding those that are cross-listed) is acceptable toward the degree.

Under Plan II-b (internship/course-based), a minimum of 33 hours of coursework, including 3 hours of Internship (PHYSCS / EECE 559), is required. This plan requires an industrial or a national/federal lab internship that lasts from six to twelve months. Students must interview with participating industry or lab representatives (under the guidance of a faculty representative or liaison) and arrange an appropriate internship. Quarterly progress reports, as well as a comprehensive final report, must be submitted by the student to a committee consisting of the faculty liaison, one other member of the Optics faculty, and the student's industrial or lab contact/supervisor. Internships would follow typical coursework plans in the first 12 to 18 months after the student has been admitted to the graduate program. 
A. Mandatory Courses

Advanced Optics I (Physics 463 or EECE 464)

Advanced Optics II (Physics 554 or EECE 567)

Laser Physics I (Physics 464 or EECE 464)

Optics Lab (Physics 476L or 477L)

Electrodynamics (Physics 511 or EECE 561)

Guided Wave Optics (EECE 564) or Optical Fiber Communication (EECE 565)

B. Optional Courses

Introduction to Optoelectronics (EECE 475)

Quantum Mechanics I (Physics 521)

Microelectronics Processing Lab (EECE 574L)

Nonlinear Optics (Physics 555 or EECE 568)

Solid State Physics(Physics 529) or Semiconductor Properties (EECE 572)

Topics in Modern Optics (Physics 569) or Special Topics (EECE 595)

Laser Physics II (Physics 564)

Semiconductor Lasers and LEDs (EECE 577)

Quantum Optics (Physics 566)

Atomic and Molecular Structure (Physics 531)

Optical Coherence Theory (Physics 556)

12 hours of coursework must be taken at 500 level or higher. Students in Plans I and Iib must submit and defend a thesis (Ia) or internship report (IIb). Students in Plan IIa must pass an oral exam. Students in Plans IIa or IIb can take at most 6 hrs of 400 level courses excluding those that are cross-listed (EECE and Physics)

\subsubsection{M.S. Oral Exam:}

3 committee members (two from the home department, one from the other department) are selected by the student to test the subjects covered in the core courses (Advanced Optics I and II, Laser I). The student has two attempts to pass the exam. The second exam must be taken between 3 and 12 months after the first attempt.

\section{New Mexico educational ladder}

The MS program introduced in 2002 is an important component of the emerging comprehensive educational infrastructure in NM that in recent years has been largely shaped by the burgeoning optics and photonics industry. The educational ladder, the focus of much recent local and national press coverage [Guenther 2002], [Pedrotti 2002], [Prasad 2003] has its roots at the middle school level, where students are being groomed to become a part of the newly established Photonics Academy at the West Mesa High School. The two-year Academy is a highly promising experiment funded by the Sandia National Laboratory to prepare a pool of high school graduates who will choose photonics-based microelectronics as a career. The TVI photonics program, alluded to earlier and the second major rung of the ladder, will be a natura*1 choice for many of these Academy graduates, the rest likely preferring to apply to four-year B.S. programs specializing in optics. Efforts are currently under way to establish a B.S. degree in Optical Science and Engineering at UNM. Such a program, if and when it becomes available, will not only furnish a useful career option to many high school students of NM but also complete the local ladder of educational programs beginning at the mid-school level and finishing at the M.S. and Ph.D. programs at UNM. By its multiple entry and exits points, the ladder empowers the aspiring students to evaluate and determine their career goals and objectives.

\section{WICHE affiliation}

In 1996, after a critical review, the optics program at UNM was selected as a regional educational and research resource for the western United States, becoming a Western Regional Graduate Program (WRGP) under the auspices of the Western Interstate Commission on Higher Education (WICHE). Only about a hundred programs spread over all specialties have attained this distinction throughout the fourteen states under the WICHE umbrella. An important practical benefit of this special status is that qualified residents of any of these states may enter any of the WRGP programs at the resident tuition rate. 


\section{Conclusions}

The University of New Mexico is celebrating the $20^{\text {th }}$ anniversary of it graduate programs in optical science and engineering. The academic program is supported by more than twenty graduate courses in optics, engineering, and optoelectronics that are offered on a regular basis.

Optics research at UNM has acquired an international reputation over the last decade, ranking consistently third in terms of papers presented at CLEO/QELS conferences. (Conference on Lasers and Electro-Optics/Conference on Quantum Electronics and Laser Science) pioneering work has originated from this program. Areas ranging from the quantum theory of laser, squeezed states, correlated emission lasers, atom cooling and trapping, and let to practical applications such as surface emitting semiconductors lasers, new material developments (thin films) for nonlinear optics, ultra-short pulse physics, and new concepts of laser gyros, to cite only a few recent examples.

In many areas, such as imaging and beam propagation, our research programs cover all steps from the theoretical and laboratory conceptual evaluation to the implementation with high-energy lasers. Such research has impact in pollution monitoring, communication, and astronomy. New techniques of optical microscopy have revealed subwavelength cellular structures embedded in highly diffusive materials. Very high field physics is being investigated with power lasers, leading for instance to multiphoton ionization, plasma generation and triggering of discharges.

\section{Acknowledgements}

Some of the work described in this paper is supported by the National Sciences Foundation under the Bridges for Engineering Education program, award \#EEC-0230150, cognizant program officer Sue Kemnitzer.

\section{References}

[Guenther 2002] A. H. Guenther and L. Pedrotti, "Let there be light for Albuquerque students", The Albuquerque Tribune, pp. C1, C3, 23 April 2002.

[Pedrotti 2002] L. Pedrotti and A. Guenther, Optics and Photonics News, vol. 13, pp. 16-17, Nov. 2002.

[Prasad 2003] S. Prasad, M. Sheik-Bahae, and A. Guenther, "Partnering in photonics", OE Magazine, vol. 3 (\#5), p. 31, May 2003. 